\title{
TRANSTIBIAL VERSUS INDEPENDENT FEMORAL TUNNEL DRILLING TECHNIQUES FOR ARTHROSCOPIC ANTERIOR CRUCIATE LIGAMENT RECONSTRUCTION EVALUATION OF FEMORAL APERTURE POSITIONING
}

\author{
Maged Abouelsoud, Haitham Kamel Haroun, and Mohamed Rezk Allam
}

Department of Orthopaedic Surgery, Faculty of Medicine - Ain Shams University, Cairo, Egypt. Corresponding author Mohamed Rezk Allam

Mobile: 01060375450

E.mail:

docallam69@gmail.com

Received: $12 / 11 / 2020$

Accepted: 9/12/2020

Online ISSN: 2735-3540

\begin{abstract}
:
Background: Although numerous clinical and cadaveric studies have compared transtibial (TT) versus tibial independent (TI) either anteromedial (AM) portal or Outside-in (OI) drilling techniques regarding anatomic femoral tunnel aperture placement in single bundle anterior cruciate ligament reconstruction (ACLR), there is no consensus on which technique offers the best anatomic position according to footprint position.
\end{abstract}

Aim of the Work: The aim of this study is to conduct a systematic review and meta-analysis for studies comparing the anatomical position of femoral tunnel aperture in single bundle ACLR using TI and TT techniques.

Methods: (PubMed, Cochrane library and Google Scholar) were searched for relative studies that evaluated femoral tunnel aperture position in patients and cadavers underwent arthroscopic single bundle ACLR. Meta-analyses were performed to pool 28 studies included in 15 outcomes measuring femoral tunnel aperture position by estimating the mean differences and their $95 \%$ confidence intervals from mean and standard deviation for each study.

Results: 48 clinical and cadaveric studies compared femoral tunnel aperture position between TT and TI (AM and OI) techniques were obtained for final research. In these studies, 2384 clinical and cadaveric knees underwent arthroscopic single bundle ACLR, we qualitatively assessed the femoral aperture position in all 48 studies showing that the difference between TI and TT was non significant except in the direction perpendicular to Blumensaat's line (BL), but with low mean difference and anteroposterior (AP) anatomical axis.

Conclusions: There was non-significant difference between TI and TT technique regarding placing femoral aperture position closer to footprint position. There was non-significant difference in femoral aperture sagittal plane position along BL or along (proximal-distal) $P D$ axis. Regarding femoral aperture coronal plane placement in the axis perpendicular to $B L$; modified TT technique improved the femoral aperture position in this axis. While regarding femoral aperture placement in the anteroposterior (AP) anatomical axis; TI technique placed femoral aperture significantly more posterior than TT technique, this was proper position regarding anatomic ACLR, while according to the recent concept of ACL femoral footprint, this might be improper position."

\section{INTRODUCTION:}

Improper femoral aperture placement is the most common cause of anterior cruciate ligament reconstruction (ACLR) failure or unsatisfactory outcomes (long term joint degeneration and re-rupture, technical errors 
have been noted in 50\% of ACL failure cases $^{(1)}$. The proportion of femoral, as opposed to tibial tunnel positioning errors is $3: 1$ because the knee's center of rotation is closer to the femoral insertion and preparation of this tunnel is considered to be one of the most complex procedures in $\operatorname{ACLR}^{(2)}$.

With further anatomical and biomechanical studies, surgeons realized the two-bundle anatomy of the ACL and the specific role of its lower, shallower fibers posterolateral (PL) bundle in its rotatory stabilizing function, accordingly, surgeons attempted to restore the native footprint especially at the femoral side, This was the concept of the double bundle ACL reconstruction techniques "Anatomical double-bundle ACLR reconstruction"(3).

Recently, there are several modifications have been introduced on conventional transtibial (cTT) technique to target femoral aperture more anatomically to the femoral footprint such as altering the tibial position in relation to the femur during femoral aperture drilling, altering the starting point of the tibial tunnel, TT technique assisted by AM portal and posterior notchplasty at over the top position. In TT technique, femoral tunnel is drilled through tibial tunnel which results in a significantly more anterior and vertical position of the femoral tunnel, to overcome the problems of TT technique, surgeons began drilling the femoral tunnel through AM portal $^{(4)}$.

The proper positioning of the femoral tunnel is much easier in AM portal technique than TT technique because the position of the femoral tunnel is restricted by the angulation of the tibial tunnel in the frontal and sagittal planes in the TT technique $^{(5)}$.

\section{METHODOLOGY:}

Search methods for identification of studies:
Electronic research: Databases searched (PubMed, Cochrane Library and Google Scholar). Searches in these databases were carried out in accordance with PRISMA (Preferred Reporting Items for Systematic Reviews and Meta-analyses ${ }^{(6)}$. There were restrictions for electronic search for studies including English language only. Searching other resources e.g. Searching references lists of the included studies.

\section{Criteria for considering studies for this review:}

\section{Characteristics of accepted studies:}

Regarding design; clinical studies: randomized controlled trials (RCT), non randomized controlled clinical trials, cohort studies, and case-control studies, basic science (cadaveric) studies: controlled laboratory experimental studies. Context those that analyze femoral aperture placement with a direct comparison of TT versus independent (AM or OI) femoral drilling techniques. Full report femoral tunnel aperture position including a suitable statistic describing average and distribution, and sample numbers. Publications in the form of an abstract, letter, or review article were not included.

\section{Characteristics of the included Participants:}

Human or cadaveric subjects (basic science), following single bundle ACL recons-truction, skeletally mature patients.

\section{Comparisons and interventions:}

Direct comparisons of TT and TI (AM portal or OI) techniques. Adequate statistical methods to compare quantified femoral aperture location resulting from TT and TI (AM portal or OI) methods of ACLR.

\section{Outcome:}

Assessment of femoral aperture position by direct measurement or by postoperative imaging: plain X-ray (PXR) and/or computerized tomography (CT) and/or 
Magnetic reasonance imaging (MRI). Femoral aperture tunnel location quantified by an appropriate method.

\section{Data collection and analysis:}

\section{Study selection:}

We reviewed the title and abstract of each publication and then performed a thorough reading of all potentially relevant articles

\section{Data extraction and management:}

Data from included studies were independently extracted into Spread sheets, including study characteristics, participants' characteristics; intervention characteristics; and outcomes of interest including femoral aperture posision with summary data of outcome in each intervention group. In case of any missing data in any study, we tried to contact the corresponding author.

\section{Statistical analysis:}

For analysis of categorical outcomes (e.g., proportion of femoral aperture inside a reference anatomical range), the effect of treatment was quantified by calculating the risk ratio (RR) and associated 95\% confidence interval $(\mathrm{CI})$.We provided a qualitative synthesis of the findings from the included studies, structured according to the imaging technique and measurement method. If enough comparative studies are provided (at least 2) using the same measurement tool on the same imaging modality, a meta-analysis was performed.

The random-effects estimate was presented with its $95 \% \mathrm{CI}$, as well as the estimates of $\mathrm{T}^{2}$ and $\mathrm{I}^{2}$. We performed these analyses using Rev Man software (version 5.3.5; Nordic Cochrane Centre, Copenhagen, Denmark).

\section{RESULTS:}

Literature search Electronic search yielded 2434 studies from three databases (PubMed, Cochrane Library and Google Scholar). After screening title/abstract, 2361 studies were excluded irrelevant to our included studies, resulting in 73 studies were screened in full text screening for inclusion criteria, and 27 studies were excluded because they included double bundle ACLR, non anatomical studies, femoral tunnel orientation, and non comparative studies. So, 46 studies are remaining from electronic search, then by manual search 2 studies were added, so 48 studies were suitable and eligible for qualitative and quantitative synthesis, out of these 48 studies there were 28 studies encountered in quantitative meta-analysis. Fig (1)

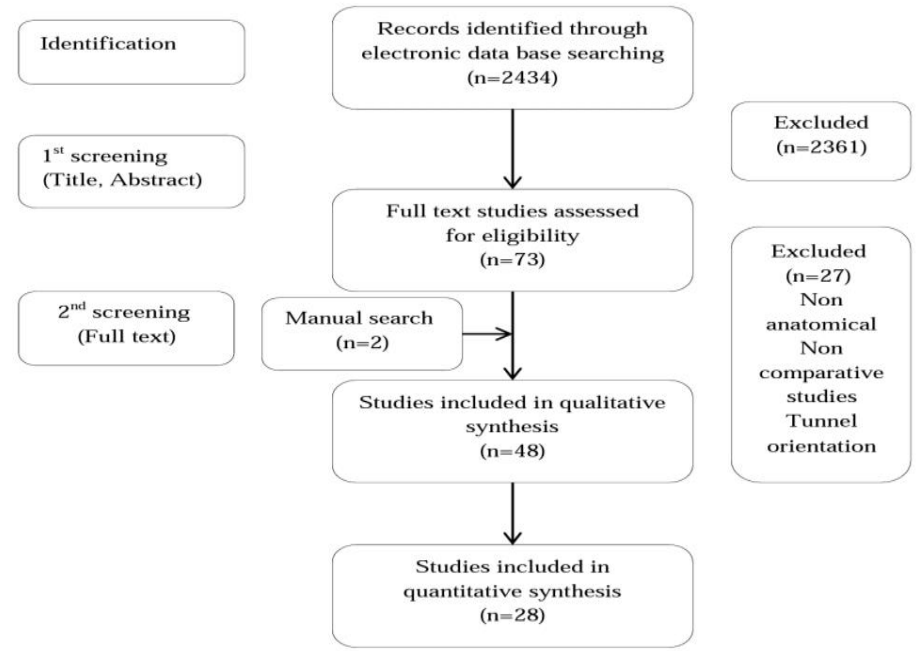

Figure (1): PRISMA flow diagram of the identification and selection of the studies included in systematic review and meta-analysis. 
Studies and participants characteristics (Table 1)

Table (1): Characteristics table for patients in the included.

\begin{tabular}{|c|c|c|c|c|c|c|}
\hline No & Study ID & $\begin{array}{l}\text { Imaging } \\
\text { Modality }\end{array}$ & $\begin{array}{c}\text { Study } \\
\text { groups }\end{array}$ & Research type & $\begin{array}{c}\text { Number of knees } \\
\text { assessed }\end{array}$ & Year \\
\hline 1 & Abebe etal, $2009^{(7)}$ & MRI \& Direct & mTT vs OI & Clinical & $16(8$ TT 8 OI $)$ & 2009 \\
\hline 2 & Ahn et al,2013 ${ }^{(8)}$ & CT & TT vs OI & Clinical & 69 (34 TT, 35 OI) & 2013 \\
\hline 3 & Albuquerque et al, $2007^{(9)}$ & Direct & TT vs AM & Basic science & $20(\mathrm{AM}, \mathrm{TT})$ & 2007 \\
\hline 4 & Arno et al,2016 ${ }^{(10)}$ & MRI & TT vs AM & Clinical & $\begin{array}{r}20(10 \mathrm{TT} \\
, 10 \mathrm{AM})\end{array}$ & 2016 \\
\hline 5 & Bedi et al, $2011^{(11)}$ & Direct & TT vs AM & Basic science & $10(5 \mathrm{AM}, 5 \mathrm{TT})$ & 2011 \\
\hline 6 & Bowers et al, $2011^{(12)}$ & MRI & TT vs AM & Clinical & $30(15 \mathrm{TT}, 15 \mathrm{AM})$ & 2011 \\
\hline 7 & Chang et al, $2013^{(13)}$ & Radiograph & $\begin{array}{l}\text { mTT vs } \\
\text { AAM }\end{array}$ & Clinical & $105(55 \mathrm{TT}, 50 \mathrm{AM})$ & 2013 \\
\hline 8 & Cho et al, $2012^{(14)}$ & Radiograph & $\begin{array}{l}\text { mTT vs } \\
\text { AAM }\end{array}$ & Clinical & $30(15 \mathrm{TT}, 15 \mathrm{AM})$ & 2012 \\
\hline 9 & Clockaert et al, $2016^{(15)}$ & CT & TT vs AM & Clinical & $32(16 \mathrm{TT}, 16 \mathrm{AM})$ & 2016 \\
\hline 10 & De Abreu Silva, 2014 ${ }^{(16)}$ & CT & TT vs AAM & Clinical & 23 (9 TT, 14 AM) & 2014 \\
\hline 11 & Francesci et al, $2013^{(17)}$ & Radiograph & TT vs AAM & Clinical & $\begin{array}{c}88(46 \mathrm{TT}, \\
42 \mathrm{AM})\end{array}$ & 2013 \\
\hline 12 & Gadikota et al, $2012^{(18)}$ & Direct & $\begin{array}{l}\text { TT vs AM } \\
\text { vs OI }\end{array}$ & Basic science & 8 (AM, TT, OI) & 2012 \\
\hline 13 & Gavriilidis et al, $2008^{(19)}$ & Direct & TT vs AAM & Basic dcience & 10(AM, TT) & 2008 \\
\hline 14 & Geng et al, $2018^{(20)}$ & CT & TT vs AM & Clinical & 104 (TT 48, AM 56) & 2018 \\
\hline 15 & Guler et al, $2016^{(21)}$ & MRI & TT vs AAM & Clinical & 48 (25 TT, 23 AM) & 2016 \\
\hline 16 & Hart et al, $2018^{(22)}$ & MRI & $\begin{array}{l}\text { mTT vs AM } \\
\text { vs AM, }\end{array}$ & Clinical & $\begin{array}{l}\text { AM } 21\left(1^{\text {st }}: 11,2^{\text {nd }}: 10\right) \\
\text { TT } 20(3 \text { rd: } 9,4 \text { th:11) }\end{array}$ & 2018 \\
\hline 17 & Hensler et al, $2013^{(23)}$ & CT & TT vs AM & Clinical & $47(27 \mathrm{TT}, 20 \mathrm{TI})$ & 2013 \\
\hline 18 & Hussin et al, $2018^{(24)}$ & Radiograph & $\begin{array}{c}\text { mTT vs } \\
\text { AAM }\end{array}$ & Clinical & 60 (30 TT, 30 AM) & 2018 \\
\hline 19 & ILllingworth, $2011^{(25)}$ & $\begin{array}{c}\text { MRI, radiograph, } \\
\text { CT }\end{array}$ & TT vs TI & Clinical & $\begin{array}{c}50(34 \mathrm{TT}, \\
16 \mathrm{TI})\end{array}$ & 2011 \\
\hline 20 & Inderhaug et al, $2016^{(26)}$ & $\mathrm{CT}$ & TT vs AAM & Clinical & $\begin{array}{c}139 \text { (TT: 41, AM1: 58, } \\
\text { AM2: 40) }\end{array}$ & 2016 \\
\hline 21 & Jennings et al, $2017^{(27)}$ & Direct & $\begin{array}{c}\text { mTT vs AM } \\
\text { vs TT }\end{array}$ & Basic science & $\begin{array}{c}12 \text { (TT 16, TT } 28 \\
\text { AM 28) }\end{array}$ & 2017 \\
\hline 22 & Jaecker etal,2017 ${ }^{(28)}$ & CT & TT vs AM & Clinical & 101 (64 TT), (37 AM) & 2017 \\
\hline 23 & Kaseta et al, $2008^{(29)}$ & Direct & TT vs OI & Basic science & $12(\mathrm{TT}, \mathrm{OI})$ & 2008 \\
\hline 24 & Larson, et, al,2012 ${ }^{(30)}$ & CT & $\begin{array}{c}\text { TT vs AM } \\
\text { vs OI }\end{array}$ & Basic science & $\begin{array}{l}20 \text { (5 for TT, } 5 \text { AM rigid } \\
\text { reamer }(\mathrm{rr}), \mathrm{AM} \text { flexible } \\
\text { reamer }(\mathrm{fr}), 5 \mathrm{OI})\end{array}$ & 2012 \\
\hline 25 & Lee D.W et al,2018 & $\mathrm{CT}$ & OI vs mTT & Clinical & $100(50 \mathrm{mTT}, 50$ OI $)$ & 2018 \\
\hline 26 & Lee J,K,et al,2014 ${ }^{(32)}$ & CT & mTT vs AM & Clinical & 104 (52 mTT, 52 AM) & 2014 \\
\hline 27 & Matassi et al, $2015^{(33)}$ & CT & TT vs OI & Clinical & $40(20 \mathrm{TT}, 20 \mathrm{OI})$ & 2015 \\
\hline 28 & Miller et al, 2011 ${ }^{(34)}$ & CT & TT vs AM & Basic science & $20(10 \mathrm{TT}, 10 \mathrm{AM})$ & 2011 \\
\hline 29 & Mirzatolooei et al, 2012 $2^{(35)}$ & Radiograph & TT vs AM & Clinical & 105 (47 TT 58 AM) & 2012 \\
\hline 30 & Noh et al, $2013^{(36)}$ & MRI & TT vs AM & Clinical & $61(30 \mathrm{TT}, 31 \mathrm{AM})$ & 2013 \\
\hline 31 & Osti et al, $2015^{(37)}$ & $\mathrm{CT}$ & $\begin{array}{l}\text { TT vs AAM } \\
\text { vs OI }\end{array}$ & Clinical & $\begin{array}{c}100(36 \mathrm{TT}, \\
(32 \mathrm{AM}, 32 \mathrm{OI})\end{array}$ & 2015 \\
\hline 32 & Pascual et al, $2013^{(38)}$ & Radiograph & TT vs AAM & Clinical & 40 (23 AM 17 TT) & 2013 \\
\hline 33 & Robert et al, $2013^{(39)}$ & $\mathrm{CT}$ & $\begin{array}{c}\text { TT vs OI vs } \\
\text { AAM }\end{array}$ & Basic science & $13(\mathrm{Am}, \mathrm{TT}, \mathrm{OI})$ & 2013 \\
\hline 34 & Seo et al, $2013^{(40)}$ & CT & TT vs OI & Clinical & $42(17 \mathrm{TT}, 25 \mathrm{OI})$ & 2013 \\
\hline 35 & Shin et al, $2013^{(41)}$ & CT & $\begin{array}{c}\text { TT vs } \\
\text { AAM vs OI }\end{array}$ & Clinical & $\begin{array}{c}153 \text { (42 TT: } 73 \text { AM, } 38 \\
\text { OI) }\end{array}$ & 2013 \\
\hline 36 & Silva et al, $2012^{(42)}$ & CT & AAM vs TT & Clinical & 40 (20 TT, 20 AAM) & 2012 \\
\hline 37 & Song et al, $2014^{(43)}$ & CT & TT vs AM & Clinical & 60 (30 TT, 30 AM) & 2014 \\
\hline 38 & Steiner et al,2009 ${ }^{(44)}$ & Direct & TT vs AM & Basic science & 20 (AM 10, TT 10) & 2009 \\
\hline
\end{tabular}


Transtibial Versus Independent Femoral Tunnel Drilling Techniques For Arthroscopic Anterior.....

\begin{tabular}{|c|c|c|c|c|c|c|}
\hline 39 & Tasdemir et al, $2015^{(45)}$ & MRI & TT vs AM & Clinical & 39 (15 TT, 24 AM) & 2015 \\
\hline 40 & Tompkis2012 $2^{(46)}$ & $\mathrm{CT}$ & TT vs AAM & Basic science & 20 (10 TT, 10 AM) & 2012 \\
\hline 41 & Tompkins, $2013^{(47)}$ & CT & TT vs AAM & Basic science & 20 (10 TT,10 AM) & 2013 \\
\hline 42 & Tudsico, $2012\left(^{48)}\right.$ & Radiograph,Direct & TT vs AM & Basic science & $12(6 \mathrm{TT}, 6 \mathrm{AM})$ & 2012 \\
\hline 43 & Venosa et al, $2017\left(^{49)}\right.$ & $\mathrm{CT}$ & TT vs AAM & Clinical & 52 (TT 26, AM 26) & 2017 \\
\hline 44 & Wolf et al, $2014^{(50)}$ & $\mathrm{CT}$ & $\begin{array}{c}\text { OI vs AM } \\
\text { vs TT }\end{array}$ & Basic science & 67 (23 TT, 23 AM, $21 \mathrm{OI})$ & 2014 \\
\hline 45 & $\mathrm{Xu}$, eta al,2011 ${ }^{(51)}$ & Radiograph & TT vs AM & Clinical & 72 (53 TT, 19 AM) & 2011 \\
\hline 46 & Yanasse et al, $2016^{(52)}$ & Radiograph & TT vs OI & Clinical & $32(14$ TT, 18 OI $)$ & 2016 \\
\hline 47 & Yau et al, $2013^{(53)}$ & MRI & TT vs AM & Clinical & 39(20 TT, 19 AM) & 2013 \\
\hline 48 & Youm et al, $2014^{(54)}$ & CT & mTT vs AM & Clinical & $40(20$ mTT, 20 AM $)$ & 2014 \\
\hline
\end{tabular}

\section{Outcome:}

Assessment of femoral aperture position in the included 48 studies, there were 28 studies included in meta-analysis.

\section{Effects of interventions (Qualitative synthesis and meta-analysis):}

Femoral aperture position could be defined by one of 2 approaches

1) Absolute definition (indirect methods: (The femoral aperture position of each technique in the lateral femoral condyle or inter condylar notch irrelevant to footprint position).

A. Coronal plane position as Percentage ratio of an overall scaling dimension from the lateral femoral condyle or the inter condylar notch.

a) Coronal plane position perpendicular to Blumensaat's line (BL):

- Using quadrant method measured on 3DCT scan; 14 studies assessed this outcome and their results were pooled in a meta-analysis $\{1\}$.

- Using quadrant method measured on radiograph $\left(\mathrm{Xu}\right.$ et $\mathrm{al},{ }^{(51)}$ found that $\mathrm{TI}$ technique placed femoral aperture at a significantly lower position than TT technique in the axis perpendicular to BL. Regarding Franceschi et al, ${ }^{(17)}$ found that femoral aperture position percentage perpendicular to BL in AM group was lower than TT group; $55 \%$ vs $22 \%$, respectively. However, no statistical comparison was performed. b) Coronal plane position along AP anatomical axis:

- Measured using ACA method on CT scan Lee, JK , Shin, and Illingworth $^{(32,41 \& 25)}$ were pooled in metaanalysis $\{2\}$

- Measured by Clock face method on axial MRI. (Gueler, Tasdemir and Yau $)^{(21,10 \& 53)}$ discussed in meta-analysis $\{3\}$.

- Measured by Clock face method directly on specimen Alburquque et al, ${ }^{(9)}$ found that there was no statistically significant difference between both group.

- Measured by method proposed by Heming $^{(55)}$ on axial CT view, Larson et al, ${ }^{(30)}$ found that OI aperture position was significantly lower than TT technique. Also demonstrated that femoral tunnel position with AM rr (rigid reamer) technique placed femoral aperture at significantly higher position than OI technique

B. Coronal plane position as distance in mm from fixed anatomic land mark:

a) On profile 3D CT view of the medial wall of the lateral femoral condyle:

- Femoral aperture inferior edge (distal anatomically) to inferior articular surface (posterior anatomically) on CT scan. we found 2 cadaveric studies Tompkins, $2013,{ }^{(47)}$ and In Larson et al, ${ }^{(30)}$ (including 30 specimen) that measured this outcome ,but the results couldn't be 
pooled, the results were inconsistent, Tompkins, found non significant difference, while Larson, found that OI was significantly closer than TT and AM rr (OI was lower).

- Femoral aperture inferior edge (posterior anatomically) to inferior edge of articular cartilage (posterior anatomically) In Miller et $\mathrm{al}^{(34)}$ distance was significantly lesser in AM group than in TT group (i.e. TI was lower).

b) On Coronal MRI; the distance from femoral aperture position to "over the top" in AP axis Noh, et al ${ }^{(36)}$ found that AM was significantly nearer to "over the top" than TT technique (AM was lower).

C. Sagittal plane position as Percentage ratio of an overall scaling dimension from the lateral femoral condyle or the intercondylar notch:

a) Sagittal plane position along BL

- Using quadrant method measured on 3DCT scan; 14 studies assessed this outcome and their results were pooled in meta-analysis. $\{4\}$

- Femoral aperture position percentage from whole BL length (Harner method) measured on radiograph (Hussinet al and Yanasse et al) ${ }^{(24 \& 52)}$ discussed in metaanalysis $\{5\}$

- Measured by quadrant method on sagittal MRI Guler and Yau (21)(53) studies were pooled in meta-analysis $\{6\}$

b) Sagittal plane position along to PD axis

- Measured using ACA method on CT scan Lee, JK , Shin, and Illingworth ${ }^{(32,}$ 41\&25) were pooled in meta-analysis $\{7\}$

- Measured by method proposed by Heming ${ }^{(55)}$ on Coronal CT view, Osti, et $\mathrm{al}^{(37)}$ found that both AM and OI aperture position were significantly more distal along PD axis than TT techniques.
D. Sagittal plane position as distance in mm from fixed anatomic land mark along PD axis:

\section{a) Measured directly on specimen:}

- Femoral aperture center to posterior articular border of the lateral intercondylar notch. Gravidiliis et al, ${ }^{(19)}$ TI aperture was significantly closer to deep articular border of lateral notch than TT technique (TI more proximal).

- Distance between femoral aperture posterior margin to posterior articular cartilage measured on cadaveric specimens (posterior wall thickness). Alburquque, ${ }^{(9)}$ proved that there was no significant difference between both groups in post wall thickness.

\section{b) Measured on profile 3D CT view of medial wall of lateral femoral condyle.}

- Distance from femoral aperture center to posterior wall on CT scan. Miller et $\mathrm{al},{ }^{(34)}$ found that the distance was significantly lesser in AM group than in TT group (i.e.AM was more proximal).

- Femoral aperture anterior edge to anterior articular surface (distal anatomically). Tompkins, 2013, ${ }^{(47)}$ found that the the distance was significantly closer for AM than TT technique (i.e. AM more distal).

2) Definition relative to femoral footprint (Direct measurement):

\section{A. Own study footprint position:}

\section{a) Footprint of the same knee:}

- On Photographed on arthroscopic image: Distance of femoral aperture center to margin of femoral ACL footprint measured on photographed arthroscopic image. Gavrillidis et, al, ${ }^{(19)}$ found that AM was significantly closer to footprint than TT technique with mean difference of $3.4 \mathrm{~mm}$ 
- On 3D model of specimen created by digitizing stylus Distance from femoral aperture center to footprint center

- Along AP and PD axes. In Gadicota, et al, ${ }^{(18)}$ and Kaseta, et al, ${ }^{(29)}$ their results were analyzed in meta-analysis $\{8\}$, $\{9\}$. While in greatest distance. In Gadicota, et al, ${ }^{(18)}$ and Kaseta, their results were analyzed in meta-analysis $\{10\}$.

- On 3D CT scan.

- Distance from center of femoral aperture to center of footprint on CT scan. We found 2 cadaveric studies Tompkins, $2012^{(46)}$ and Robert (39) (including 33specimens) that measured this outcome, we decided not to pool their results together because of different methodology in defining the femoral footprint during analysis of femoral aperture site on the same knee specimen.

\section{b) Footprint of the contralateral knee on MRI reconstructed knee model mirrored and its osseous geometry aligned with contralateral intact knee model:}

- Difference in AP and PD position percentage between femoral aperture and femoral footprint where AP and PD position in each group was measured by a method that could be translated to anatomical coordinate axis method on MRI. Arno et al, ${ }^{(10)}$ found that in the AP position percentage difference was equivalent between the TT and AM groups but regarding the PD \% , TT group was more proximal than the intact ACL.
- Distance in anatomic coordinate axes (in $\mathrm{AP}$ and PD axes). Abebe and Bowers ${ }^{(7 \& 12)}$ data results were analyzed in metaanalysis $\{11$ and 12$\}$

- Femoral aperture distance to femoral footprint center in greatest (hypotenuse) distance. Abebe, Bower and Hart ${ }^{(7,12 \& 22)}$ their results were analyzed in metaanalysis $\{13\}$

\section{Reference anatomical footprint position:}

a) Proportion of femoral aperture outside a referenced anatomic range formed by Forsythe et al ${ }^{(56)}$ measured by anatomic coordinate axis method. Hensler et al., ${ }^{(23)}$ and Illingworth et $\mathrm{al}^{(25)}$ were included in meta-analysis $\{14\}$.

b) Proportion of outliers from an anatomical femoral aperture height measured by clock face method $(\leq 11$ o'clock for a right knee (or $\geq 1$ o'clock for a left knee which was equivalent to $\leq 330^{\circ}$ for a right knee (or $\geq 30^{\circ}$ for a left knee (No reference cited). Tasdemir et al., ${ }^{(45)}$ and $\mathrm{Yau}$ et $\mathrm{al},{ }^{(53)}$ found significantly less outliers in AM than TT group. These 2 studies were included in meta-analysis $\{15\}$.

Effect of intervention (Metaanalysis): 28 studies were included in metaanalysis analyzed for 15 outcomes as following:

1) Femoral aperture coronal plane position perpendicular to (BL) using quadrant method on CT scan. 14 studies fulfilled the criteria for review of this outcome. (Fig 2) 


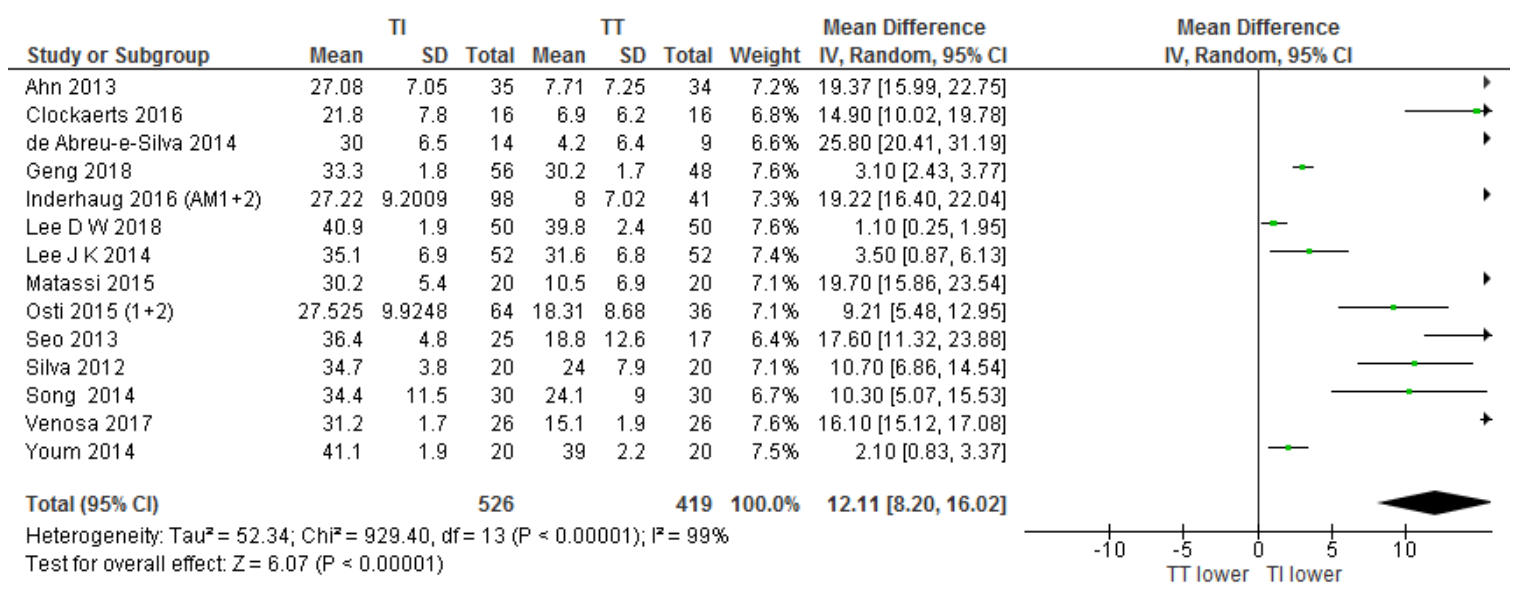

Figure (2): Forest plot of comparison: femoral tunnel aperture height on CT scan.

TI technique placed femoral aperture $12.11 \%$ lower than TT technique, $(95 \% \mathrm{CI})$ was $(8.2 \%$ lower to $16.02 \%$ lower). The difference was statistically significant $(\mathrm{P}<0.00001)$. There was sever heterogeneity $\left(\mathrm{I}^{2}\right)=99 \%$.

2) Femoral aperture coronal plane position along AP axis measured using ACA method on CT scan. In 3 studies $^{(25,32 \& 41)}$, TI technique placed femoral aperture $13.95 \%$ more posterior than TT technique, $95 \% \mathrm{CI}$ was $(1.86 \%$ more posterior to $25.98 \%$ more posterior). The difference was statistically significant $(\mathrm{P}=0.02)$.
3) Femoral aperture coronal plane position along AP anatomical axis using Clock face method measured on axial cut MRI. In 3 studies $^{(21,45 \& 53)}$, TI technique placed femoral aperture $19.15^{\circ}$ more posterior angle than TT technique, $95 \%$ CI $\left(24.13^{\circ}\right.$ more posterior to $14.18^{\circ}$ more posterior). The difference was statistically significant $(\mathrm{P}<0.00001)$.

4) Femoral aperture sagittal plane position along (BL) using quadrant method on CT scan: 14 studies fulfilled the criteria for review of this outcome (Fig 3)

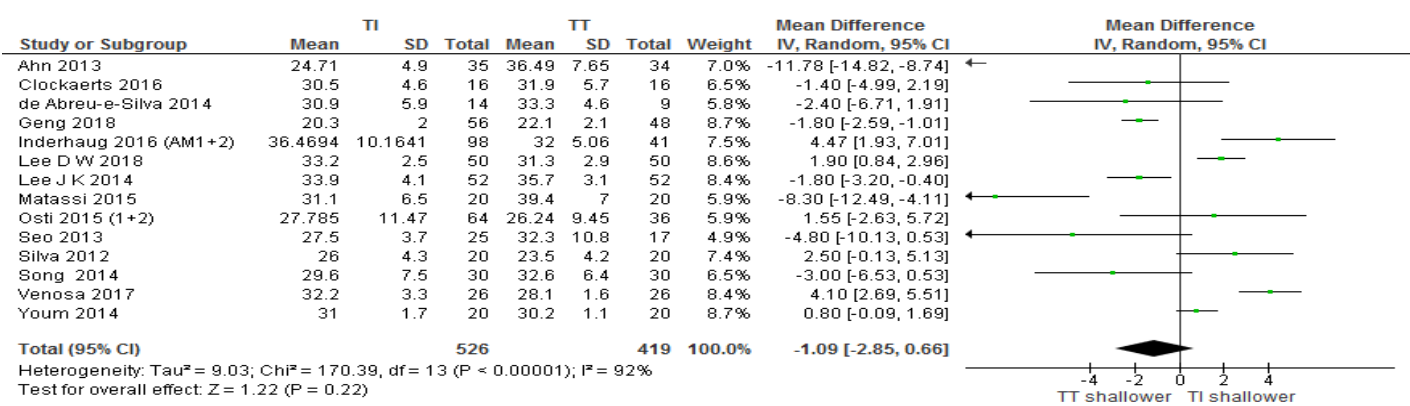

Figure (3): Forest plot of comparison: (Quadrant method for femoral aperture depth on CT scan).

TI technique placed femoral aperture $1.09 \%$ deeper than TT technique $(95 \%$ CI) was $(2.85 \%$ deeper to $0.66 \%$ shallower), however the difference was statistically non significant.

5) Femoral aperture sagittal plane position $\%$ from whole BL using Harner method measured on radiograph. In 2 studies
${ }^{(24 \&, 52)}$ TI technique placed femoral aperture $12.5 \%$ shallower than TT technique, CI 95\% (9.92\% shallower to $15.08 \%$ shallower). The difference was statistically significant $(\mathrm{P}<.00001)$. There was no heterogeneity $\left(\mathrm{I}^{2}=0 \%\right)$.

6) Femoral aperture sagittal plane position along BL by quadrant method measured 
on MRI. In 2 studies $^{(21 \& 53)}$, TI technique placed femoral aperture $2.89 \%$ deeper than TT technique, $95 \%$ CI $(5.86 \%$ deeper to $0.08 \%$ shallower), however this difference was statistically insignificant $(\mathrm{P}=0.6)$.

7) Femoral aperture sagittal position along proximal to distal axis using anatomic coordinate axis on CT scan. In 3 studies $^{(25,32 \&, 41)}$, TI technique placed femoral aperture $0.58 \%$ more distal than TT technique, 95\% CI (1.46\% more proximal to $2.62 \%$ more distal), however; the difference was statistically non significant $(\mathrm{P}=0.58)$.

8) Distance from femoral aperture center to the same knee footprint center along AP axis, on digitized 3D model of specimen. In 2 studies $^{(18 \& 29)}$,TI technique placed femoral at $3.27 \mathrm{~mm}$ more posterior distance from footprint than TT technique, 95\% CI $(6.2 \mathrm{~mm}$ more posterior to $0.33 \mathrm{~mm}$ more posterior. The difference was statistically significant $(\mathrm{P}=0.03)$.

9) Distance from femoral aperture center to the same knee footprint center in PD axis on digitized 3D model of specimen. In 2 studies $^{(18 \&}{ }^{29)}$, TI technique placed femoral aperture at $2.88 \mathrm{~mm}$ more distal distance from footprint than TT technique, $95 \%$ CI was $(6.06 \mathrm{~mm}$ more distal to $0.3 \mathrm{~mm}$ more proximal). However difference was non significant $(\mathrm{P}=0.08)$.

10) Greatest distance from femoral aperture center to the same knee footprint center on digitized 3D model of specimen. In 2 studies ${ }^{(18 \& 29)}$ fulfilled the criteria for review of this outcome. TI technique placed femoral aperture at $3.95 \mathrm{~mm}$ distance closer to footprint than TT technique, $95 \%$ CI (8.29 $\mathrm{mm}$ closer to $1.12 \mathrm{~mm}$ farther), however this difference was statistically non significant $(\mathrm{P}=0.14)$.
11) Femoral aperture distance to contralateral femoral footprint center along AP plane on MRI. in 2 studies ${ }^{(7 \& 12)}$, TI technique placed femoral aperture at $3.49 \mathrm{~mm}$ more posterior distance from footprint than TT technique, $95 \%$ CI $(8.21 \mathrm{~mm}$ more posterior to $1.24 \mathrm{~mm}$ more anterior), however this difference was statistically non significant $(\mathrm{P}=0.15)$.

12) Femoral aperture distance to contralateral femoral footprint center in (Proximal to distal) plane using MRI. in 2 studies ${ }^{(7 \& 12)}$ TI technique placed femoral aperture at $1.56 \mathrm{~mm}$ more distal distance from footprint than TT technique, 95\% CI (6.01 $\mathrm{mm}$ more distal to $2.89 \mathrm{~mm}$ more proximal), however; this difference was statistically non significant $(\mathrm{P}=0.49)$.

13) Femoral aperture center to contralateral femoral footprint center greatest distance (hypotenuse) measures on MRI. In 3 studies $^{(7,12 \& 22)}$ TI technique placed femoral aperture at $1.38 \mathrm{~mm}$ closer to footprint than TT technique, 95\% CI $(5.65 \mathrm{~mm}$ closer to $2.88 \mathrm{~mm}$ farther), however; the difference was statistically non significant $(\mathrm{P}=0.52)$.

14) Proportion of femoral aperture outside reference anatomic range according to (Forsythe et al) $^{(56)}$ In 2 studies $^{(25 \& 23)}$,TI technique significantly lowered the risk of apertures outside the referenced anatomic range by $80 \%$ than TT technique, $95 \%$ CI (92\% low risk to $53 \%$ low risk), the difference was statistically significant $(\mathrm{P}=0.0003)$.

15) Proportion of outliers from referenced anatomical femoral aperture height measured by clock face method. In 2 studies $^{(53 \& 45)}$ TI technique lowered the risk of femoral apertures outside the referenced anatomical range by $93 \%$. $95 \%$ CI $(99 \%$ low risk to $51 \%$ low risk). This difference was statistically significant $(\mathrm{P}=0.007)$. 


\section{DISCUSSION:}

Regarding the ability of each technique to achieve the footprint center position; Directly comparing the distance of aperture center placed by each technique to footprint center of the same knee on digitized $3 \mathrm{~d}$ model showed non significant difference in 48 specimens of 2 studies ${ }^{(18 \& 29)}$ On 87 patients of 3 studies ${ }^{(7,12 \&}$ 22) assessing the ability of each technique to recreate the footprint position of the contralateral knee on MRI, there was non significant difference in distance of aperture center to footprint center. Contradictory to the pervious findings, aperture placed by TI technique was significantly closer, albeit by small difference of $2.4 \mathrm{~mm}$ and $4 \mathrm{~mm}$, in two studies using CT scan and including 59 specimens $^{(39 \& 46)}$.

Regarding the ability of each technique to achieve the proper footprint coronal plane position along AP anatomical axis on digitized 3D model of 48 specimens of 2 studies (18\& 29) showed that TI technique placed aperture at less anterior distance from footprint than TT technique, albeit with a small difference of $3.3 \mathrm{~mm}$. Contradictory to the pervious findings, there was non significant difference between both techniques in recreating the AP footprint position of the contralateral knee in two studies using MRI and including 46 participants $^{(7 \& 12) \text {. }}$

Regarding the axis perpendicular to $\mathrm{BL}$, assessing the spatial position In footprint referenced to BL, the apertures placed by TI and TT techniques were in lower deep quadrant in $70 \%$ and $50 \%$ of specimens, respectively, in one study including 20 specimens and using CT scan ${ }^{(46)}$.

Regarding the ability of each technique to achieve the proper footprint sagittal plane position, regarding $\mathrm{PD}$ anatomical axis, there was non significant difference between both techniques in recreating the PD footprint position of the same knee assessed on digitized 3D model in two studies including 48 specimens ${ }^{(18 \& 29)}$.

Regarding the direction along BL, Comparing the ability of each technique to achieve a reference anatomical position, one study ${ }^{(8)}$ used Frosythe's reference anatomical position $^{(56)}$ along BL (28.4\%) in a clinical study on 69 patients and found that TI technique placed the aperture center $11.7 \%$ deeper and closer to the referenced position than TT technique.

Regarding the difference in coronal position of femoral aperture placed by each technique in the axis perpendicular to BL, in 14 studies including 990 patients, TI technique significantly lowered the position of the placed aperture by $11.3 \%$ (95\% CI $7.9 \%$ lower to $14.7 \%$ lower) than the TT technique as measured by quadrant method on 3D CT. A consistent finding as demonstrated on 52 patients of 1 study ${ }^{(51)}$ where TI technique significantly lowered the position of the placed aperture than the TT technique as measured by Quadrant method on radiography.

While along AP anatomical axis, in 3 studies ${ }^{(25,32 \& 41)}$ including 307 patients, TI technique placed femoral aperture in significantly more posterior position than TT technique with mean difference of $13.9 \%$ (95\% CI of $1.9 \%$ to $29 \%$ ) as measured by anatomic coordinate axis method on 3D CT. A radiological study ${ }^{(36)}$ using MRI performed on 61 participants demonstrated that the posterior margin of aperture placed by TI technique was significantly at more posterior distance from the over-the-top point than TT technique with mean difference of $7 \mathrm{~mm}$. Contradictory to these findings, there were inconsistent results of qualitative synthesis of results of 2 studies (30\&47) assessing the distance of aperture inferior edge to inferior articular surface on profile 3D CT view of medial wall of LFC of 40 specimens. 
Regarding the difference in sagittal position of femoral aperture placed by each technique, in the axis along BL. On 990 patients (14 studies), there was non significant difference between both techniques in the position of placed aperture along BL as measured by quadrant method on $3 \mathrm{D} \mathrm{CT}$. Using the same measurement method on radiography and MRI, a consistent result was demonstrated on 72 patients 1 study, ${ }^{(51)}$ and 87 patients (2 studies; ${ }^{(21 \& 53)}$ respectively.

While in the axis along PD anatomical axis, on 307 patients ( 3 studies $(25,32 \& 41)$ there was non significant difference between both techniques in the PD position of placed aperture as measured by anatomic coordinate axis method on 3D CT. Contradictory to that, on 100 patients included in 1 study ${ }^{(37)}$, TI technique placed femoral aperture at a significantly more distal position than the TT technique as measured by clock face method on CT coronal view. Non significant difference was demonstrated in 3 studies; $(9, \quad 30 \& 36)$ Contradictory to that a significant difference between both techniques was demonstrated. The direction of that intervention effect was diverse among studies.

\section{Conclusion:}

There was non-significant difference between TI and TT techniques in the distance from femoral aperture center to footprint center. Regarding placement in the direction perpendicular of $\mathrm{BL}$, TI technique placed femoral aperture in lower deep quadrant a little bit more than TT technique and significantly lowered the position of the placed aperture than TT technique, but the mean difference looked clinically insignificant. Regarding placement along AP anatomical axis, TI technique placed Femoral aperture at less anterior distance from footprint than TT technique with a small difference and placed femoral aperture in a more posterior position than TT technique and the difference looked clinically significant. Regarding sagittal plane placement of femoral aperture along AP anatomical axis and along BL, there was nonsignificant difference between both techniques.

\section{REFERENCES}

1. Jorge PB, Escudeiro D, Severino NR, Santili C, Paula R De, Cury L, et al. Positioning of the femoral tunnel in anterior cruciate ligament reconstruction : functional anatomical reconstruction. 2018;5-8.

2. Wang Y, Fu S, Ph D, Hopkins C, Sc B, Yung $S$, et al. A Systematic Review of Anterior Cruciate Ligament Femoral Footprint Location Evaluated by Quadrant Method for Single-Bundle and DoubleBundle Anatomic Reconstruction. 2016;111.

3. Musahl V, Plakseychuk A, VanScyoc A, Sasaki T, Debski RE, McMahon PJ, et al. Varying femoral tunnels between the anatomical footprint and isometric positions: Effect on kinematics of the anterior cruciate ligaments-reconstructed knee. Am J Sports Med. 2005;33(5):712-8.

4. Evidence L V. Cruciate Ligament Femoral Tunnel. 2008;24(1):113-5.

5. Georgoulis A, Bernard M. The Anteromedial Portal for Drilling of the Femoral Tunnel for Anterior Cruciate Ligament Reconstruction. 2005;20(3):2289.

6. Tawfik GM, Agus K, Dila S, Yousif M, Mohamed F. A step by step guide for conducting a systematic review and metaanalysis with simulation data. 2019;6:1-9.

7. Tunnel $\mathrm{T}$, Techniques I, Abebe ES, Iii CTM, Dziedzic TS, Spritzer CE, et al. Femoral Tunnel Placement During Anterior Cruciate Ligament Reconstruction An In Vivo Imaging Analysis Comparing Transtibial. 2009;37(10):1904-11.

8. Ahn JH, Jeong HJ, Ko C, Ko TS, Kim JH. Three-Dimensional Reconstruction Computed Tomography Evaluation of Tunnel Location during Single-Bundle Anterior Cruciate Ligament Reconstruction: A Comparison of Transtibial and 2-Incision 


\section{Maged Abouelsoud, et al.,}

Tibial Tunnel-Independent Techniques. 2013; 26-35.

9. Freire R, Amatuzzi MM, Pacheco P, Angelini FJ, Jr OC. Basic Research Positioning Of The Femoral Tunnel For Arthroscopic Reconstruction Of The Anterior Cruciate Ligament: Comparative Study Of 2 Techniques. 2007;62(5):613-8.

10. Arno S, Bell CP, Alaia MJ, Bs BCS, Jazrawi LM, Walker PS, et al. Does Anteromedial Portal Drilling Improve Footprint Placement in Anterior Cruciate Ligament Reconstruction? Clin Orthop Relat Res. 2016;474(7):1679-89.

11. Bedi A, Musahl V, Steuber V, Kendoff D, Choi D, Allen AA, et al. Cruciate Ligament Reconstruction: An Anatomic and. YJARS [Internet]. 2011;27(3):380-90. Available from: http://dx.doi.org/10. 1016/j.arthro. 2010. 07.018

12. Rodeo SA, Pearle AD, Warren RF, Altchek DW. Comparison of Anterior Cruciate Ligament Tunnel Position and Graft Obliquity With Transtibial and Anteromedial Portal Femoral Tunnel Reaming Techniques Using High-Resolution Magnetic Resonance Imaging. YJARS [Internet]. 2011;27(11):1511-22. Available from: $\quad \mathrm{http}: / / \mathrm{dx}$.doi.org/10.1016/j.arthro. 2011. 07.007

13. Lee KJ, Lee $\mathrm{K}$, Kim $\mathrm{TK}, \mathrm{Ph} \mathrm{D}$. Comparisons of Femoral Tunnel Position and Length in Anterior Cruciate Ligament Reconstruction: Modified Transtibial Versus Anteromedial Portal Techniques. YJARS [Internet]. 2011;27(10):1389-94. Available from: http://dx.doi.org/10.1016/j. arthro.2011.06.013

14. Cho Y, Cho J, Kim D. Normal sagittal of the anterior cruciate ligament can be reproduced using accessory anteromedial portal technique: a magnetic resonance imaging study. 2012;1011-9.

15. Clockaerts S, Haver A Van, Verhaegen J, Vuylsteke K, Leenders T, Lagae KC, et al. The Knee Transportal femoral drilling creates more horizontal ACL graft orientation compared to transtibial drilling: A 3D CT imaging study. Knee [Internet]. 2016; 8-15. Available from: http://dx.doi. org/10.1016/j.knee.2016.02.014

16. Abreu-e-silva GM De, Baumfeld DS, Bueno LR, Pfeilsticker RM, Ant^ M. SC. Knee [Internet]. 2014; Available from: http://dx.doi.org/10.1016/j.knee.2014.05.00 4

17. Franceschi F, Papalia R, Rizzello G, Buono A Del, Maffulli N, Ph D, et al. Anterior Cruciate Ligament Reconstruction: Any Clinical. Arthrosc J Arthrosc Relat Surg [Internet]. 2013;29(8):1330-7. Available from: http://dx.doi.org/10.1016/j.arthro. 2013. 05.020

18. Gadikota HR, Sim JA, Hosseini A, Gill TJ, Li G. The Relationship Between Femoral Tunnels Created by the Transtibial, Anteromedial Portal , and Outside-In Techniques and the Anterior Cruciate Ligament Footprint. 2012;882-8.

19. Gavriilidis I, Motsis EK, Pakos EE, Georgoulis AD, Mitsionis G, Xenakis TA. Transtibial versus anteromedial portal of the femoral tunnel in ACL reconstruction: A cadaveric study. 2008;15:364-7.

20. Geng Y, Gai P. Comparison of 2 femoral tunnel drilling techniques in anterior cruciate ligament reconstruction . A prospective randomized comparative study . 2018;0:1-7.

21. Guler O, Mah M, Mehmet M, Cerc H. Graft position in arthroscopic anterior cruciate ligament reconstruction: anteromedial versus transtibial technique. 2016;

22. Hart A, Sivakumaran T, Burman M, Powell T, Martineau PA. A Prospective Evaluation of Femoral Tunnel Placement for Anatomic Anterior Cruciate Ligament Reconstruction Using 3-Dimensional Magnetic Resonance Imaging. :192-9.

23. Tashman $\mathrm{S}, \mathrm{Fu} F H$, Hon $\mathrm{D}$, Hon $\mathrm{D}$. Correlation Between Femoral Tunnel Length and. 2013;2029-34.

24. Hussin EA, Aldaheri A, Alharbi H, Farouk HA. Modified transtibial versus anteromedial portal techniques for anterior cruciate ligament reconstruction, a comparative study. 2018;199-213.

25. Illingworth KD, Hensler D, Working ZM, Macalena JA, Tashman S, Fu FH. A Simple 
Evaluation of Anterior Cruciate Ligament Femoral Tunnel Position The Inclination Angle and Femoral Tunnel Angle. :2611-8.

26. Inderhaug E, Larsen A, Strand T, Arne P, Eirik W. The effect of feedback from post operative 3D CT on placement of femoral tunnels in single - bundle anatomic ACL reconstruction. Knee Surgery, Sport Traumatol Arthrosc. 2016;24(1):154-60.

27. Jennings JK, Leas DP, Fleischli JE, Alessandro DFD, Peindl RD, Piasecki DP. Transtibial Versus Anteromedial Portal ACL Reconstruction Is a Hybrid Approach the Best ? 2017;1-11.

28. Jaecker V, Zapf T, Thomas JN. High nonanatomic tunnel position rates in ACL reconstruction failure using both transtibial and anteromedial tunnel drilling techniques. Arch Orthop Trauma Surg. 2017;137 (9): 1293-9.

29. Kaseta MK, Scd LED, Ab BLC, Sullivan RT, Jr WEG. Reconstruction Technique Affects Femoral Tunnel Placement in ACL Reconstruction. 2008;1467-74.

30. Larson AI, Bullock DP, Pevny T. Comparison of 4 Femoral Tunnel Drilling Techniques in Anterior Cruciate Ligament Reconstruction. YJARS [Internet]. 2012; 28(7):972-9. Available from: http://dx.doi. org/10.1016/j.arthro.2011.12.015

31. Lee DW, Kim JG, Ph D, Lee JH, Park JH, Kim DH. Cruciate Ligament Reconstruction. Arthrose J Arthrosc Relat Surg [Internet]. 2018;34(10):2857-70. Available from: https://doi.org/10.1016/j.arthro.2018. 05.041

32. Jk L, Lee S, Sc S, Mc L. Anatomic SingleBundle ACL Reconstruction Is Possible with Use of the Modified Transtibial Technique. 2014;664-72.

33. Matassi F. J oints Anatomical anterior cruciate ligament reconstruction: SIGASCOT Best Paper Award Finalist 2014 J oints. 2015;3(1):6-14.

34. Miller CD, Gerdeman AC, Hart JM, Ph D, Bennett CG, Golish SR, et al. A Comparison of 2 Drilling Techniques on the Femoral Tunnel. YJARS [Internet]. 2018;27(3):372-9. Available from: http:// dx.doi. org/10.1016/j.arthro. 2010. 08. 012
35. Article O. Comparison of short term clinical outcomes between transtibial and transportal TransFix ${ }^{\circledR}$ femoral fixation in hamstring ACL reconstruction. 2012;46 (5): 361-6.

36. Yi SR, Ph D, Lee SY. Femoral Tunnel Position on Conventional Magnetic Resonance Imaging After Anterior Cruciate Ligament Reconstruction in Young Men: Transtibial Technique Versus Anteromedial Portal Technique. Arthrosc J Arthrosc Relat Surg [Internet]. 2013;29(5):882-90. Available from: http://dx.doi.org/10.1016/j. arthro.2013.01.025

37. Osti M, Krawinkel A, Ostermann M, Hoffelner T, Benedetto KP. Femoral and Tibial Graft Tunnel Parameters After Transtibial , Anteromedial Portal, and Outside-In Single-Bundle Anterior Cruciate Ligament Reconstruction. 2015;2250-8.

38. Swanson CPBL, Swanson KE. Transtibial versus low anteromedial portal drilling for anterior cruciate ligament reconstruction : a radiographic study of femoral tunnel position. 2013;846-50.

39. Robert HE, Bouguennec N, Vogeli D, Berton E, Bowen M. Coverage of the Anterior Cruciate Ligament Femoral Footprint Using 3 Different Approaches in Single-Bundle Reconstruction A Cadaveric Study Analyzed by 3-Dimensional Computed Tomography. 2013;41(10): 2375-83.

40. Seo SS, Kim CW, Kim JG, Jin SY. Clinical Results Comparing Transtibial Technique and Outside in Technique in Single Bundle Anterior Cruciate Ligament Reconstruction. 2013;25(3):133-40.

41. Portal A, Techniques O. Location of the Femoral Tunnel Aperture in Single-Bundle Anterior Cruciate Ligament Reconstruction. :2533-9.

42. Silva A, Sampaio R, Pinto E. ACL reconstruction: comparison between transtibial and anteromedial portal techniques. 2012;896-903.

43. Song E, Kim S, Lim H. Comparisons of tunnel-graft angle and tunnel length and position between transtibial and transportal techniques in anterior cruciate ligament 


\section{Maged Abouelsoud, et al.,}

reconstruction. 2014;2357-62.

44. Steiner ME, Battaglia TC, Heming JF, Rand JD, Pt P, Festa A, et al. Independent Drilling Outperforms Conventional Transtibial Drilling in Anterior Cruciate Ligament Reconstruction. 2008;1912-9.

45. Does the anteromedial portal provide clinical superiority compared to the transtibial portal in anterior cruciate ligament reconstruction in nonprofessional athletes in. 2015;49(5):483-91.

46. Tompkins M, Milewski MD, Brockmeier SF, Gaskin CM, Hart JM, Miller MD. Anatomic Femoral Tunnel Drilling in Anterior Cruciate Ligament Reconstruction Use of an Accessory Medial Portal Versus Traditional Transtibial Drilling. 2012;131321.

47. Brockmeier SF, Hart JM, Ph D, Miller MD. Anterior Cruciate Ligament Reconstruction Femoral Tunnel Characteristics Using an Accessory Medial Portal Versus Traditional Transtibial Drilling. Arthrosc J Arthrosc Relat Surg [Internet]. 2018;29(3):550-5. Available from: http://dx.doi.org/10.1016/j. arthro. 2012.10.030

48. T C, B S. Drilling the Femoral Tunnel During ACL Reconstruction: Transtibial Versus. :1166-72.

49. Venosa M, Delcogliano M, Padua R, Alviti F, Delcogliano A. Femoral Tunnel Positioning in Anterior Cruciate Ligament Reconstruction: Anteromedial Portal versus Transtibial Technique - A Randomized Clinical Trial. 2017;34-8.

50. Wolf BR, Amendola A. Anterior Cruciate Ligament Tunnel Placement. 2014;
(January).

51. Yu J, Ph D, Cui G. Relation of Tunnel Enlargement and Tunnel Placement After Single-Bundle Anterior Cruciate Ligament Reconstruction. 2011;27(7):923-32.

52. Yanasse RH, Lima AA, Antoniassi RS, Ezzedin DA, Henrique M, Laraya F, et al. Original article Transtibial technique versus two incisions in anterior cruciate ligament reconstruction: tunnel positioning, isometricity and functional evaluation $\approx$. Rev Bras Ortop [Internet]. 2016;51(3):27481. Available from: http://dx.doi.org/10. 1016/j.rboe. 2016.04.001

53. Yau Wpmbbsfrcsefhkcosfhkam, M Awmfmbcbfrcsefhkcosfhka, E Dkhymbbsmrcs. Tunnel Positions in Transportal Versus Transtibial Anterior Cruciate Ligament Reconstruction: A CaseControl Magnetic Resonance Imaging Study. Arthrosc J Arthrosc Relat Surg [Internet]. 2013;29(6):1047-52. Available from: http://dx. doi.org/10.1016/j. arthro. 2013. 02.010

54. Youm Y, Cho S, Lee S. Modified Transtibial Versus Anteromedial Portal Technique in Anatomic Single-Bundle Anterior Cruciate Ligament Reconstruction Comparison of Femoral Tunnel Position and Clinical Results. 2014;2941-7.

55. Heming JF, Rand J, Steiner ME. Anatomical Limitations of Transtibial Drilling in Anterior Cruciate Ligament Reconstruction. :38-40.

56. Tashman S, Fu FH, Hon D, Hon D. The Location of Femoral and Tibial Tunnels in. 2010;(805):1418-26. 
مراجعة منهجية وتحليل بعدى لما تم نشره من أبحاث مقارنة حفر النفق الفخذي عن طريق القصبة مقابل الحفر

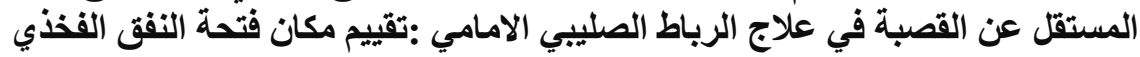

$$
\begin{aligned}
& \text { ماجد أبو السعود، هيثم كامل هارون، عحمث رزق علام } \\
& \text { قسم جر احة العظام، كلية الطب - جامعة عين شمس }
\end{aligned}
$$

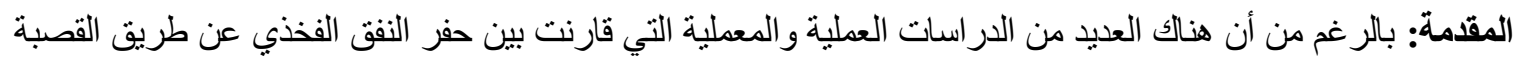

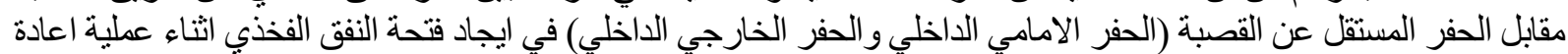

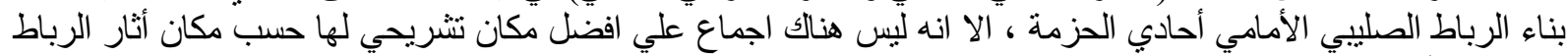
الصليبي الأمامي.

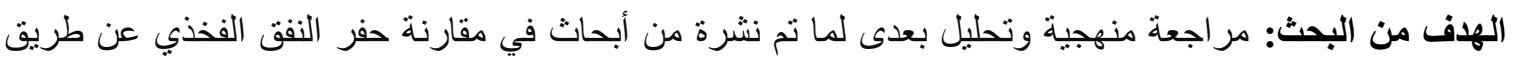

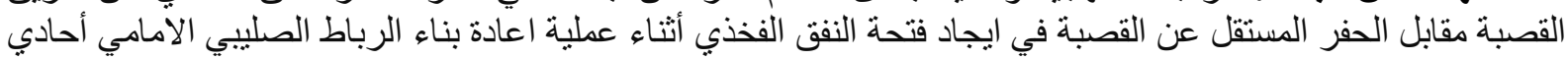

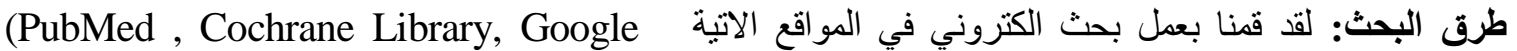

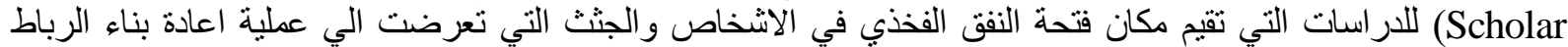
الصليبي الامامي احادي الحزمة بالمنظار.

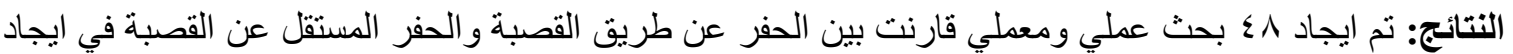

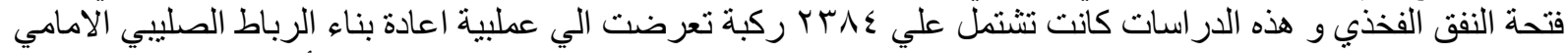

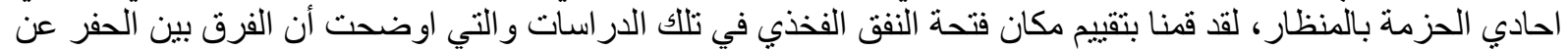

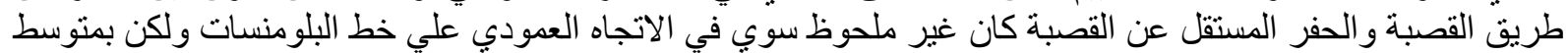
اختلاف طفيف و أيضا في الاتجاه الأمامي الخلفي التشريحي.

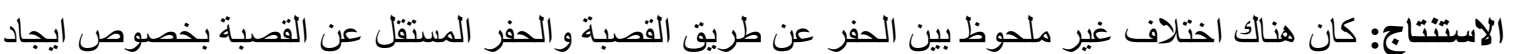

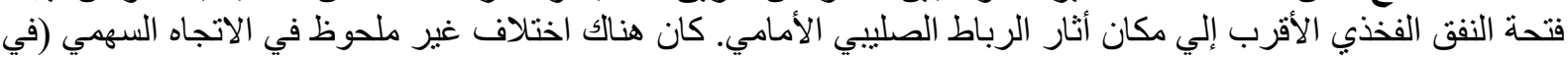

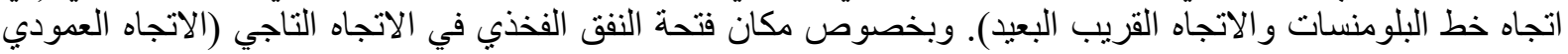

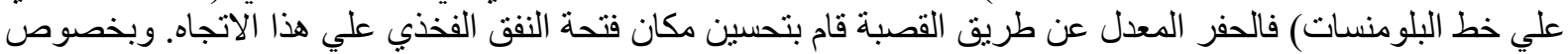

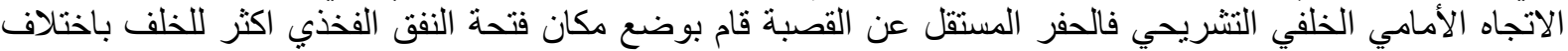

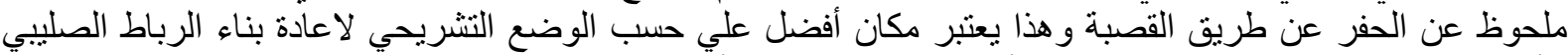

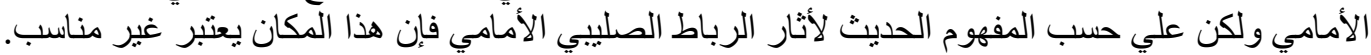

